\title{
Correction \\ Correction: David et al. Effects of Transient Loss of Vision on Head and Eye Movements during Visual Search in a Virtual Environment. Brain Sci. 2020, 10, 841
}

\author{
Erwan David *(D), Julia Beitner (D) and Melissa Le-Hoa Võ (D) \\ Scene Grammar Lab, Department of Psychology, Theodor-W.-Adorno-Platz 6, Johann \\ Wolfgang-Goethe-Universität, 60323 Frankfurt, Germany; beitner@psych.uni-frankfurt.de (J.B.); \\ mlvo@psych.uni-frankfurt.de (M.L.-H.V.) \\ * Correspondence: david@psych.uni-frankfurt.de
}

check for updates

Citation: David, E.; Beitner, J.; Võ,

M.L.-H. Correction: David et al.

Effects of Transient Loss of Vision on Head and Eye Movements during

Visual Search in a Virtual

Environment. Brain Sci. 2020, 10, 841.

Brain Sci. 2021, 11, 1215.

https://doi.org/10.3390/

brainsci11091215

Received: 6 May 2021

Accepted: 30 August 2021

Published: 15 September 2021

Publisher's Note: MDPI stays neutral with regard to jurisdictional claims in published maps and institutional affiliations.

Copyright: (C) 2021 by the authors. Licensee MDPI, Basel, Switzerland. This article is an open access article distributed under the terms and conditions of the Creative Commons Attribution (CC BY) license (https:/ / creativecommons.org/licenses/by/ $4.0 /)$.
We wish to make the following correction to the published paper "Effects of Transient Loss of Vision on Head and Eye Movements during Visual Search in a Virtual Environment" [1].

We have identified a flaw in the implementation of a latency mitigation strategy for our gaze-contingent protocol written in Unity3D. As a result, the maximum latency is now estimated to be $30 \mathrm{~ms}$ instead of $15 \mathrm{~ms}$, which should not affect any of the results originally published but should be noted for further reference.

Funding: This study was supported by the Deutsche Forschungsgemeinschaft (DFG, German Research Foundation), project number 222641018 SFB/TRR 135 TP C7 granted to MLHV.

Conflicts of Interest: The authors declare no conflict of interest.

\section{Reference}

1. David, E.; Beitner, J.; Võ, M.L.-H. Effects of Transient Loss of Vision on Head and Eye Movements during Visual Search in a Virtual Environment. Brain Sci. 2020, 10, 841. [CrossRef] 